\title{
ANÁLISE DE PROCESSOS DE LICENCIAMENTO AMBIENTAL DE EMPREENDIMENTOS DE CARCINICULTURA NO ESTADO DA BAHIA, BRASIL
}

\author{
FERRAZ, C. V. H. ${ }^{1 *} \&$ FILHO, S. S. A ${ }^{2}$ \\ 1. Universidade Federal da Bahia (UFBA) \\ 2. Departamento de Engenharia Ambiental, Universidade Federal da Bahia (UFBA) \\ *Autor correspondente: carlinha.hage@gmail.com
}

\begin{abstract}
Ferraz, C. V. H. \& Filho, S. S. A. (2019). Analysis of Environmental Licensing Processes of Shrimp Farms in the State of Bahia, Brazil. Braz. J. Aquat. Sci. Technol. 23(1). elSSN 1983-9057. DOI: 13439/bjast.v23n1. The shrimp farming has undergone a great expansion in recent years, in which the State of Bahia has been playing an important role in the national context. This expansion has generated many benefits but also major concerns about its increasing environmental impacts. Considering the potential of the Environmental Licensing (EL) to induce necessary measures to achieve the sustainability requirements, this research was developed with the objective of analyzing the execution of the EL of shrimp farming in the State of Bahia and its contributions to the sustainable development. In this purpose, $15 \mathrm{EL}$ processes required in the State of Bahia were analyzed, aiming to evaluate the practices of assessment of the competent agencies and their contributions to the insertion of the objectives of sustainability in the EL of the activity. Because the available processes referred to regularization licenses, the analysis of the preventive character of the EL was impaired. The results suggest that the Technical Opinions emphasize the aspects related to the effects of the activity on the environment, which demonstrates an analysis behavior of the environmental agency based on corrective actions. The social aspects were, in general, the most neglected, in the Technical Opinions analyzed. The analysis of the required conditions in the issued also suggests a significant deficiency, reinforcing the need for important information and conditions to be required before the release of the licenses to ensure compliance. While recent legal regulations about the EL of the sector have brought some breakthroughs in addressing sustainability, their implications have not yet been sufficient to reverse the current scenario.
\end{abstract}

Key Words: Aquaculture, Shrimpfarming, Sustainable development, Environmental management.

\section{INTRODUÇÃO}

O consumo mundial de pescado vem aumentando constantemente e em contrapartida, a pesca mundial extrativista parece ter alcançado seu limite por conta de práticas de pesca não sustentáveis. Nesse contexto, a aquicultura surge como alternativa para compensar o colapso da produção pesqueira extrativista e da crescente demanda por produtos aquáticos (Santos \& Mattos, 2009).

Dentre as diversas espécies cultivadas na aquicultura, um dos ramos mais fortes é a carcinicultura, a criação de crustáceos. Em 2014 a produção brasileira de camarão alcançou 90.000 toneladas, no qual a Região Nordeste correspondia a $99 \%$ da produção nacional (Rocha, 2015). Segundo a ABCC (Associação Brasileira de Criadores de Camarão), a Bahia é o terceiro estado em produção de camarão, com uma área produtiva de 1850 hectares (Bahia Pesca, 2016).

Em busca de maiores produções de pescado, o governo brasileiro lançou, em 2015, o "Plano de Desenvolvimento daAquicultura Brasileira-2015/2020", com o objetivo de aumentar a produção aquícola brasileira para 2 milhões de toneladas até o ano de 2020 , dos quais 200.000 toneladas seriam apenas decamarão(MPA, 2015). Diante de toda essa expectativa pelo aumento da produção de camarão no Brasil e estando a Bahia como o terceiro estado produtor, torna-se claro a necessidade de maiores preocupações com a gestão da atividade e seus impactos sobre o meio ambiente.

Essa demanda por pescados tem impulsionado planos de aquicultura em moldes semelhantes ao que ocorreram nos países do sudeste asiático, sem ordenamento e regulamentação adequados, apresentando preocupações apenas com o crescimento da atividade e dos lucros, o que vem causando grandes impactos ambientais e sociais (Montibeller, 2003; Meireles et al., 2007).

Os principais impactos ambientais da carcinicultura incluem: consequências ecológicas da conversão de ecossistemas naturais, particularmente os manguezais, para construção de tanques; poluição de águas costeiras pela liberação de efluentes; salinização de águas subterrâneas; poluição por uso de produtos químicos; entre outros. Somado a estes, ainda existem impactos de amplitude sociais, como: privatização do espaço público; ocupação desordenada da lâmina d'água; limitação de acesso aos ambientes aquáticos; e interferência na cultura de comunidades pesqueiras (Assad \& Bursztyn, 2000; FAO, 2006; Scherer et al., 2010).

Para pensar em desenvolvimento sustentável torna-se indispensável que qualquer produção esteja 
aliada a ecologia local, respeitando a biodiversidade, o uso da água e da terra e considerar os diversos fatores de forma integrada. Neste sentido, é imprescindível o papel regulador do poder público, efetuando uma maior atenção para a gestão dessa atividade e estabelecendo requisitos necessários para a busca de uma produção sustentável.

Para isso, existem vários instrumentos da gestão ambiental que se fossem devidamente implementados poderiam ser os grandes direcionadores nessa busca, como é o caso do Licenciamento Ambiental (LA), que tem como objetivo compatibilizar empreendimentos e atividades consideradas efetivas ou potencialmente poluidoras com os critérios capazes de garantir a sua sustentabilidade sob o ponto de vista biofísico e social.

O LA deve, primeiramente, atuar como um procedimento de regulação preventiva com vistasaavaliar as possibilidades de compatibilização entre os impactos ambientais adversos e as restrições e/ou capacidade de suporte dos recursos ambientais envolvidos (Lima, 2004; Oliveira, 2012; Agra Filho, 2014).

Dados de 2011 mostram que entre os 1.545 produtores brasileiros cadastrados apenas, $21 \%$ dos empreendimentos aquícolas possuíam licenciamento (Rocha, 2015).

A regulamentação do licenciamento ambiental para a atividade de carcinicultura só veio a se concretizar duas décadas depois da implantação do licenciamento ambiental, com a Resolução CONAMA n ${ }^{\circ} 312$ de 10 de outubro de 2002 (Brasil, 2002), que dispõe sobre o licenciamento ambiental dos empreendimentos de carcinicultura na zona costeira. De acordo com a mesma, a classificação dos empreendimentos individuais se faz em categorias, conforme a efetiva dimensão da área inundada.

Nesse contexto normativo, vale ressaltar o grande impacto advindo do novo Código Florestal, Lei no 12.651 (Brasil, 2012), que dispõe sobre a proteção da vegetação nativa e trouxe novas implicações no direcionamento dos órgãos ambientais quanto ao problema dos empreendimentos já consolidados em Áreas de Preservação Permanente - APP. No Art. $61^{\circ}$ é estabelecido que "nas Áreas de Preservação Permanente, é autorizada, exclusivamente, a continuidade das atividades agrossilvipastoris, de ecoturismo e de turismo rural em áreas rurais consolidadas até 22 de julho de 2008". Abrindo brecha para que empreendimentos aquícolas, anteriores a 2008, que estão localizados em manguezais e outras APP possam ser licenciados. Outra resolução de grande impacto no Licenciamento da aquicultura foi a Resolução CONAMA n 459/2013 (Brasil, 2013), que passa a autorizar a criação de espécies alóctones ou exóticas desde que sejam apresentadas medidas de mitigação dos impactos potenciais, afastando os obstáculos normativos para produção dessas e outras espécies não nativas.

De acordo com Lima (2004), a eficácia do licenciamento depende também de outros instrumentos de gestão ambiental, a exemplo do zoneamento ecológico-econômico, uma necessidade para que no planejamento das políticas públicas direcionadas para carcinicultura no litoral da Bahia se considere, tanto os aspectos socioeconômicos, quanto os biofísicos, de forma a evitar os conflitos no momento da análise ambiental dos empreendimentos. No caso específico do cultivo do camarão marinho, o planejamento eficaz da ocupação espacial, contribuirá significativamente para a prática do desenvolvimento sustentável (Lima, 2004).

Desde 2000, o documento "Gestão dos Recursos Naturais: subsídios à elaboração da Agenda 21 brasileira" já pontuou que os principais problemas existentes para a execução adequada do licenciamento ambiental se referem à desestruturação dos órgãos ambientais em termos qualitativo equantitativo de pessoal para atendimento da demanda e às limitações para o acompanhamento de atividades licenciadas; à reduzida participação da sociedade no processo e à não-internalização das questões ambientais nas empresas. Em um contexto em que há escassez de recursos e de pessoal, torna-se uma tarefa impossível realizarumacompanhamento deatividades comomínimo de qualidade possível (Bezerra \& Munhoz, 2000).

Diante de tantas preocupações quanto ao futuro ambiental do Brasil e considerando o potencial do LA para o alcance de uma carcinicultura orientada para a sustentabilidade, o objetivo da presente pesquisa foi analisar a execução do procedimento do LA da carcinicultura no Estado da Bahia e suas contribuições para a sustentabilidade.

\section{MATERIAIS E MÉTODOS}

Para selecionar os processos a serem analisados nessa pesquisa foram considerados os seguintes critérios: a) empreendimentos de carcinicultura que tivessem processos analisados antes e depois do ano de 2012, ano marcado por significativas mudanças legislativas por conta do novo Código Florestal Lei $n^{\circ}$ 12.651/2012 (Brasil, 2012) e do Decreto Estadual $\mathrm{n}^{\circ}$ 14.024/2012 (Bahia, 2012); b) processos com mais informações e análises técnicas disponíveis); c) processos com certas diferenças que implicassem na forma de proceder ao licenciamento, como diferenças de porte e casos de processos de licenças deferidas e indeferidas.

A partir dos critérios considerados foram selecionados 6 empreendimentos, cada um com pelo menos 2 processos à serem analisados, totalizando 15 processos, como mostra o quadro 1. 
Quadro 1 - Empreendimentos e processos analisados.

\begin{tabular}{|c|c|c|c|c|}
\hline Empreendimento & Porte $^{*}$ & Processo & Código & Situação \\
\hline \multirow{2}{*}{$x_{10}$} & \multirow{2}{*}{ Pequeno } & 2005-000590/TEC/LS-0063 & A1 & Indeferido \\
\hline & & 2013.001.000194/INEMA/LIC-00194 & $\mathrm{A} 2$ & Arquivado \\
\hline \multirow{2}{*}{ B } & \multirow{2}{*}{ Pequeno } & 2003-005287/TEC/LS-1088 & B1 & Deferido \\
\hline & & 2014.001.000649/INEMA/LIC-00649 & B2 & Arquivado \\
\hline \multirow[b]{2}{*}{ C } & \multirow{2}{*}{ Médio } & 2004-006281/TEC/LS-1189 & $\mathrm{C} 1$ & Indeferido \\
\hline & & 2014.001.001411/INEMA/LIC-01411 & $\mathrm{C} 2$ & Arquivado \\
\hline \multirow{2}{*}{ D } & \multirow{2}{*}{ Grande } & 2002-003414/TEC/LO-0038 & $\mathrm{D} 1$ & Deferido \\
\hline & & 2009-016195/TEC/LO-0064 & $\mathrm{D} 2$ & Deferido \\
\hline \multirow{3}{*}{$\mathrm{E}$} & \multirow{3}{*}{ Grande } & 2002-001693/TEC/LO-0031 & E1 & Deferido \\
\hline & & 2004-001470/TEC/LA-0012 & $\mathrm{E} 2$ & Deferido \\
\hline & & 2009-018089/TEC/LO-0072 & E3 & $\begin{array}{c}\text { Em } \\
\text { apreciação }\end{array}$ \\
\hline \multirow{4}{*}{$\mathrm{F}$} & \multirow{4}{*}{ Grande } & 2000-003978/TEC/LO-0093 & F1 & Deferido \\
\hline & & 2004-001471/TEC/LA-0013 & F2 & Deferido \\
\hline & & 2006-005230/TEC/LO-0110 & F3 & Arquivado \\
\hline & & 2011-000984/TEC/LO-0011 & $\mathrm{F} 4$ & $\begin{array}{c}\text { Em } \\
\text { apreciação }\end{array}$ \\
\hline
\end{tabular}

(*) Porte baseado na Resolução CEPRAM n 14.024/2012 (Bahia, 2012).

Dos 15 processos selecionados, 6 são considerados atuais (A2, B2, C2, D2, E3 e F4) por serem posteriores ao novo Código Florestal Lei ${ }^{\circ} 12.651 / 2012$ (Brasil, 2012) e do Decreto Estadual $n^{\circ} 14.024 / 2012$ (Bahia, 2012) e os demais foram considerados como antigos. Para o estudo de cada processo foram considerados os itens de análise: informações requeridas; pareceres técnicos (PT) e relatórios de inspeção (RI); e condicionantes. Vale ressaltar, que o processo E1 não foi encontrado no momento em que foi solicitado para estudo, sendo analisado somente as condicionantes.
Cumpre salientar, entretanto, que apesar dos critérios e preocupações considerados nos casos selecionados, ressente-se de alguns aspectos que permitiriam maior densidade à sua representatividade. Isso decorre, basicamente, das limitações e da carência de informações sistematizadas e consolidadas em nível estadual, uma vez que a plataforma SEIA(Sistema Estadual de Informações Ambientais) disponível no site do órgão ambiental para o acesso ao público possui poucos processos disponibilizados até então.

\section{RESULTADOS}

\section{Informações requeridas}

Para analisar as informações requeridas pelo ÓrgãoAmbiental nos processos estudados na pesquisa, com base no Roteiro de Caracterização de Médio Impacto exigido pelo Instituto de Meio Ambiente e Recursos Hídricos - INEMA, as mesmas foram relacionadas às informações mínimas necessárias requisitadas pelo órgão ambiental. Cada processo, indicado no quadro 2 , informa se a informação foi requerida de forma suficiente (S), se foi pedido apenas algumas informações relativas ao item, de forma parcial $(P)$, não requerida $(N)$ ou se a informação não cabe ser requerida para tal processo (NC). As informações indicadas foram vinculadas aos processos e a data de entrada do LA.

Quadro 2 - Classificação das Informações requisitadas pelo órgão ambiental.

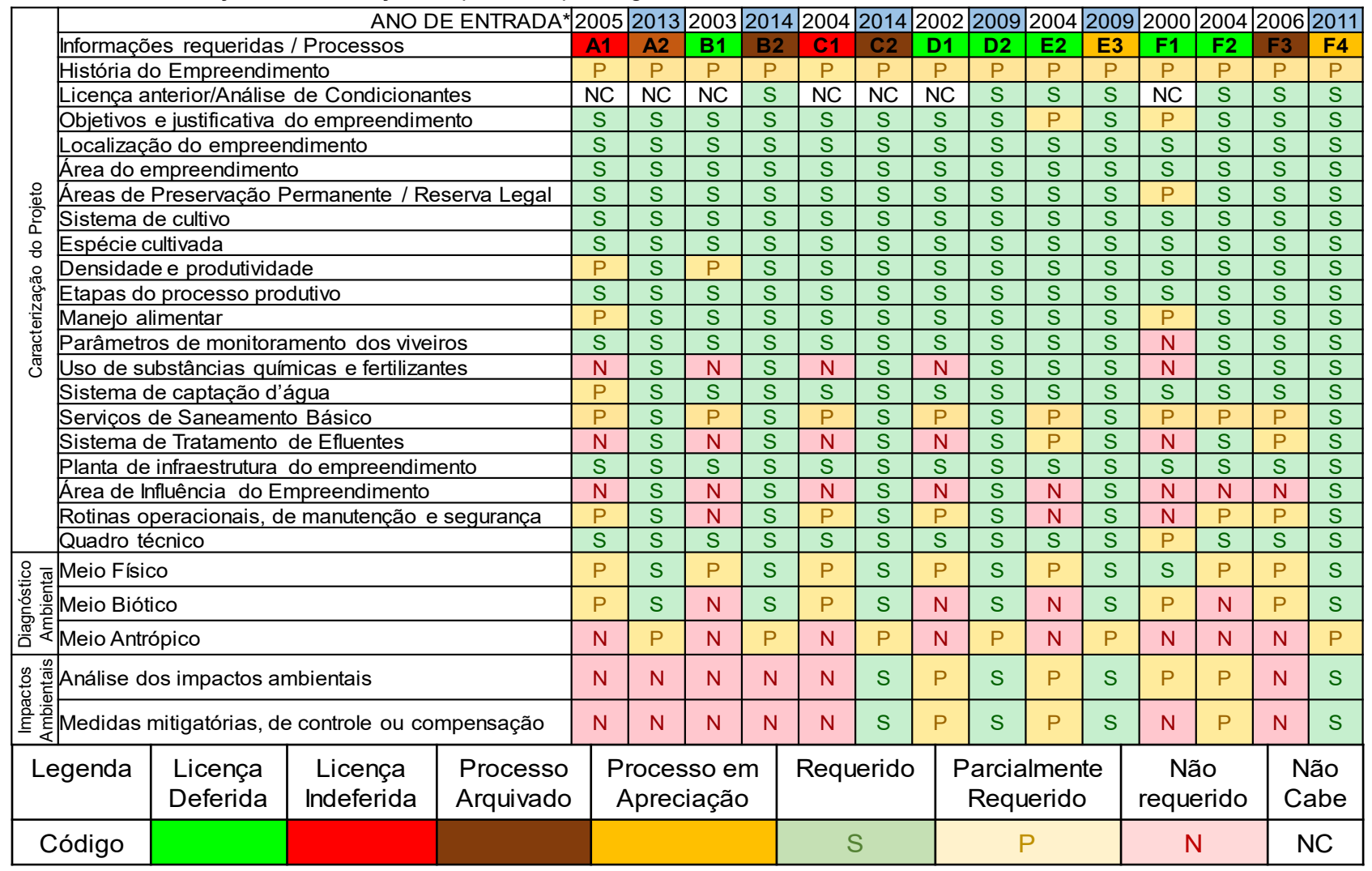

(*) Os processos considerados como atuais (após 2012) possuem seu ano de entrada em destaque na cor azul. 
A análise do quadro (2) e das figuras (1 e 2) sugerem as seguintes inferências:

- Os critérios relativos à "caracterização do empreendimento" são os mais requisitados independente do período, ressaltando que os processos atuais foram mais contemplados.

- Alguns critérios relativos à "caracterização do empreendimento" mostraram um maior número de requerimentos nos processos atuais, tais como: o uso de substâncias químicas e fertilizantes; serviços de saneamento básico; sistema de tratamento de efluentes; área de influência do empreendimento; e rotinas operacionais, de manutenção e segurança.

- Os critérios relativos ao "diagnóstico ambiental" mostraram bastante evolução ao se comparar processos antigos e atuais, exceto o meio antrópico que apesar da pequena evolução, ainda continua com requisições insuficientes.

- Os critérios relativos aos "impactos ambientais" também mostraram evolução no que diz respeito aos empreendimentos de maiores portes (a partir do empreendimento $C$ ). Isso não se aplica aos de menores portes (empreendimentos $A$ e B), pelo fato do órgão considerar que quanto menor o porte e potencial poluidor/degradador, menor a necessidade de informações, assim não costumam requisitar informações relativas a "impactos ambientais".

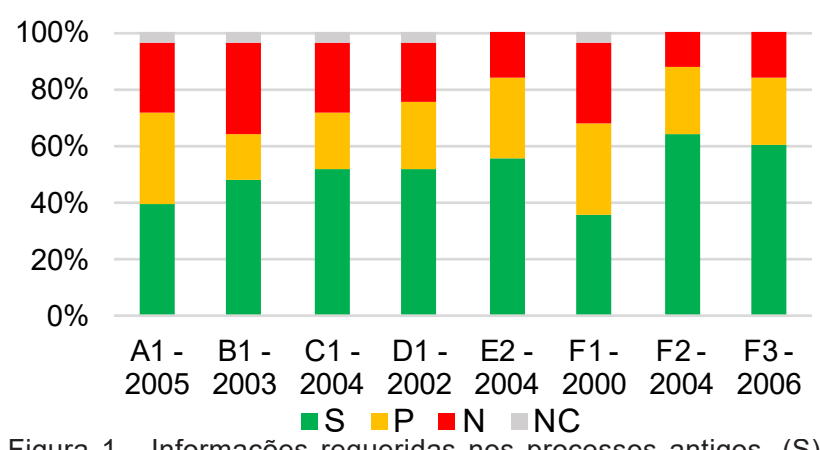

Figura 1 - Informações requeridas nos processos antigos. (S) Requerido. (P) Parcialmente requerido. (N) Não requerido. (NC) Não cabe.

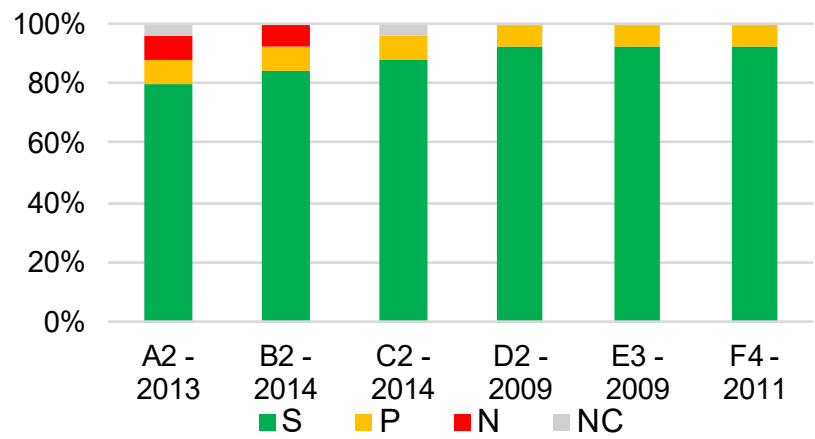

Figura 2-Informações requeridas nos processos atuais. (S) Requerido. (P) Parcialmente requerido. (N) Não requerido. (NC) Não cabe.

De forma geral, os resultados sugerem que os processos atuais estão requerendo mais informações do que os antigos (como mostram as figuras 1e2), sobretudo nos itens relativos aos grupos "diagnóstico ambiental" $e$ "impactos ambientais". Estes resultados podem refletir a evolução das normas e procedimentos associados ao empreendimento.

\section{Pareceres Técnicos e Relatórios de Inspeção}

Para cada processo dessa pesquisa foram analisados os Pareceres Técnicos (PT) e os Relatórios de Inspeção (RI) disponíveis, embora em alguns processos não constavam ambos. Para esta análise, foram consideradas como critério as informações constantes nestes documentos e a forma de apreciação pelos técnicos responsáveis. Os resultados estão sistematizados no quadro 3.

Para categorizar esses critérios foi adotado a seguinte ponderação: apenas descritos (D), apreciados (A), apreciado e proposto condicionantes (AC), apenas aparece como condicionante $(C)$, item não mencionado $(\mathrm{N})$, item não cabe ao processo (NC). Uma escala de cores foi utilizada para distinguir o nível de apreciação dos itens nos pareceres, conforme legenda indicada, desse modo, os itens classificados como: não mencionados (N) ou apenas descritos (D), nos quais não foram constatados nenhuma análise, foram agrupados pela cor vermelha; condicionantes $(C)$ sem nenhuma apreciação no corpo do parecer, foram dispostos em amarelo; apreciados (A ou $A C$ ), pois pode-se detectar uma análise crítica, foram destacados pela cor verde.

De modo geral foi possível notar uma relação proporcional entre o aumento no número de itens apreciados e o porte dos empreendimentos. Os de pequeno porte $(A$ e $B$ ) tiveram menos itens apreciados do que $o$ de médio porte $(C)$, e consequentemente dos de grande porte (D, E e F). As exceções foram os processos F2 e F3, que apesar de serem de um empreendimento de grande porte, não apresentaram apreciações por parte dos técnicos. O processo D2 merece um destaque ao ser notável a quantidade de itens apreciados ao comparar aos demais. Esse é o único processo finalizado do grupo dos atuais, no qual o parecer foi apreciado e a licença deferida em 2018.

A partir dos gráficos a seguir pode-se visualizar melhor a situação por grupos de itens apreciados, no qual se percebe o grande predomínio das cores vermelha e amarela, indicando a porcentagem alta dos itens sem uma apreciação no parecer.

Em relação ao histórico do empreendimento (figura 3), ao retirar os processos que não cabiam apreciação, apenas metade (5 de 10) dos processos apresentaram apreciação dos processos/licenças anteriores, em torno de $43 \%$ (6 de 14) apreciou-se as multas e notificações anteriores e apenas 37,5\% (3 de 8) apresentaram apreciações sobre o cumprimento das condicionantes propostas na licença anterior. 
Quadro 3. Classificação das informações dos Relatórios de Inspeção (RI) e/ou Pareceres Técnicos (PT).

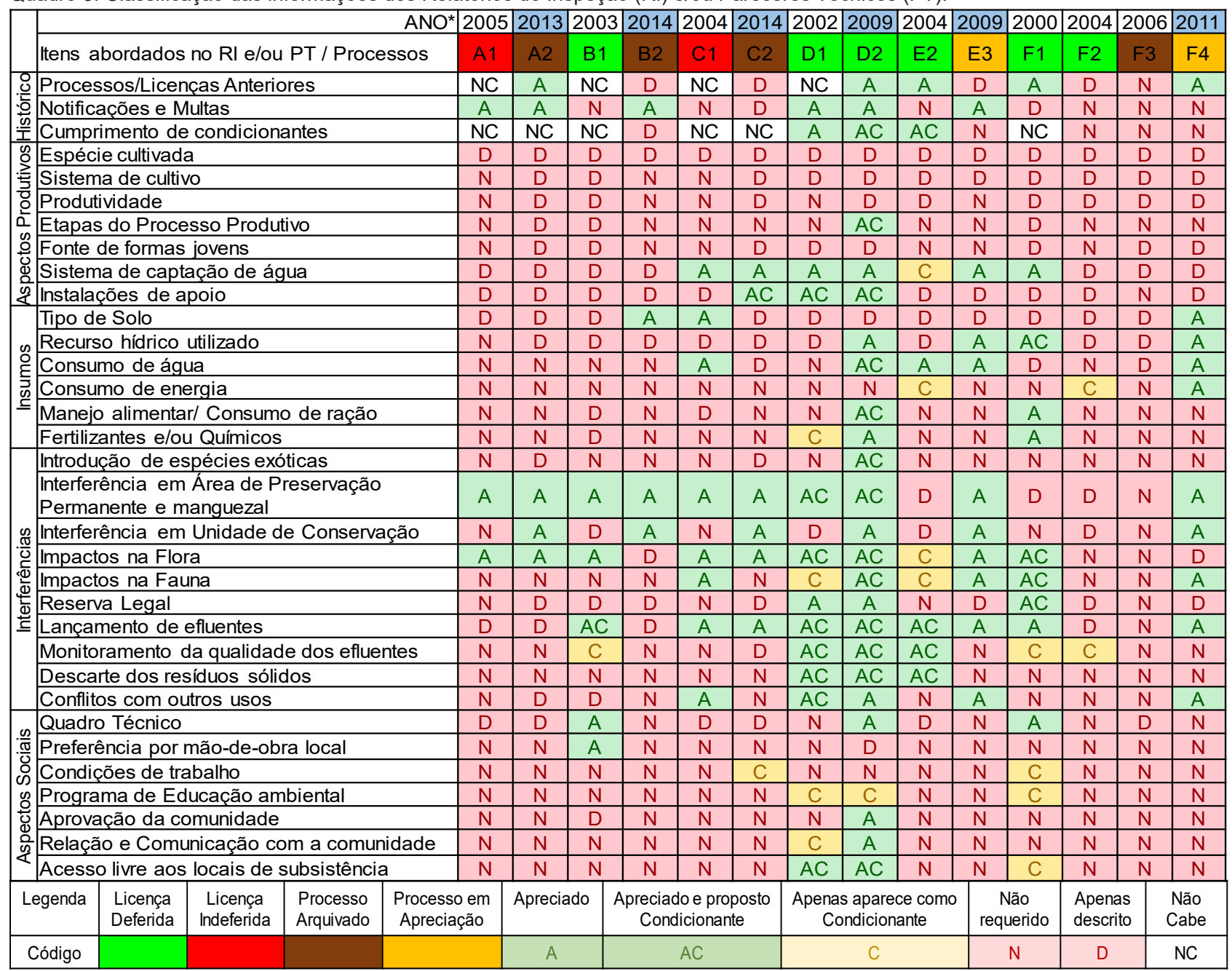

$\left({ }^{*}\right)$ Os processos atuais possuem seu ano de entrada em destaque na cor azul.

Ressalta-se que todos os processos, com exceção de um, possuem atos de advertência ou penalidades na tentativa de obrigá-los a se regularizarem e alguns conseguiram liminar judicial ou mandato de segurança para continuar atuando sem licença até a finalização dos processos.

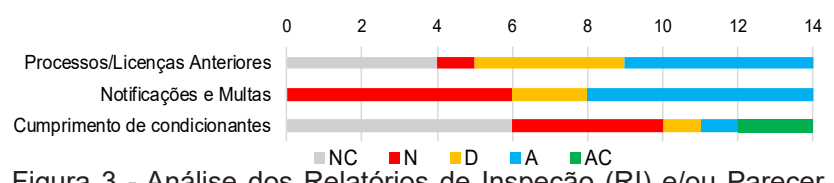

Figura 3 - Análise dos Relatórios de Inspeção (RI) e/ou Parecer Técnico (PT) dos itens do Histórico dentre os 14 processos estudados. (NC) Não cabe. (N) Não mencionado. (D) Apenas descrito. (A) Apreciado. (AC) Apreciado e proposto condicionante.

$\mathrm{Na}$ consideração dos aspectos produtivos (figura 4), se observa que grande parte dos itens apresentaram nenhum tipo de apreciação ou nem foram mencionados, com exceção do sistema de captação de água, que foi apreciado ou apareceu como condicionante em $50 \%$ dos processos analisados, as instalações de apoio que foram apreciadas em cerca de $21,5 \%$ (3 de 14) dos pareceres e o processo produtivo foi apreciado em apenas um dos processos (7\%). A restrita relevância dessas informações sugere que não se prioriza nas apreciações a perspectiva de incorporação de tecnologias mais limpas.

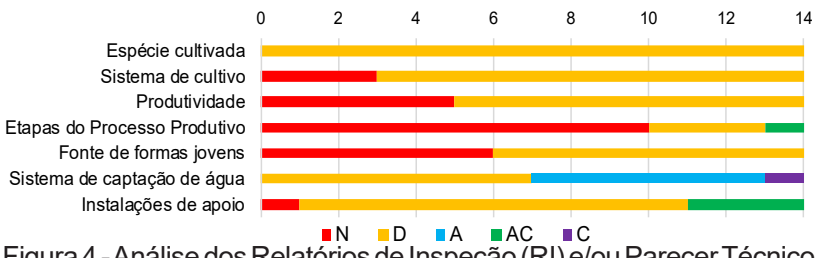

Figura 4 -Análise dos Relatórios de Inspeção (RI) e/ou Parecer Técnico (PT) dos itens dos Aspectos Produtivos dentre os 14 processos estudados. (N) Não mencionado. (D)Apenas descrito. (A) Apreciado. (AC) Apreciado e proposto condicionante. (C) Apenas aparece como condicionante.

No caso do grupo dos insumos (figura 5), os itens foram apreciados numa faixa de $7 \%$ (2 de 14) a $36 \%$ (5 de 14), no qual, os itens relacionados a água foram mais apreciados e o consumo de energia foi o mais negligenciado, aparecendo algumas vezes apenas como condicionante, sem nenhuma discussão no corpo do parecer. 


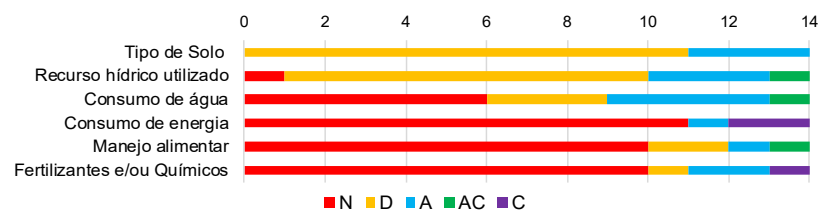

Figura 5-Análise dos Relatórios de Inspeção (RI)e/ou Parecer Técnico (PT) dos itens dos Insumos dentre os 14 processos estudados. Análise dos insumos. (N) Não mencionado. (D) Apenas descrito. (A) Apreciado. (AC) Apreciado e proposto condicionante. (C) Apenas aparece como condicionante.

O grupo das interferências (figura 6) foi o mais apreciado em relação aos demais grupos. Com exceção dos impactos relativos a criação de espécies exóticas, item apreciado em apenas 1 processo e que deveria ser alvo de apreciação ao menos nos processos antigos pelo fato que não se tinha a liberação da criação de espécies exóticas claramente constada em normas (Brasil, 2013). Vale ressaltar que 10 dos 14 processos (71\%) apresentaram apreciações do impacto sobre APP e manguezal, inclusive, esse item foi algo determinante para o indeferimento de 2 dos processos antigos. A mesma porcentagem de apreciação é constatada para impactos na Flora e em seguida com 64\% (9 de 14) de apreciações aparecem os lançamentos de efluentes.

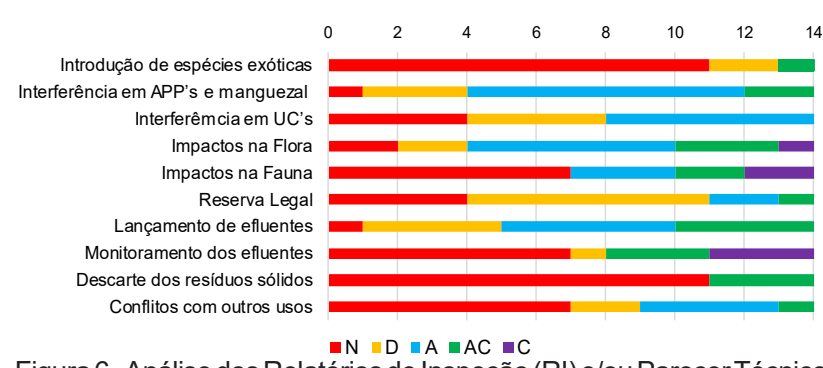

Figura 6-Análise dos Relatórios de Inspeção (RI) e/ou Parecer Técnico (PT) dos itens das Interferências dentre os 14 processos estudados. (N) Não mencionado. (D) Apenas descrito. (A) Apreciado. (AC) Apreciado e proposto condicionante. (C) Apenas aparece como condicionante. (APP's) Áreas de Preservação Permanente. (UC's) Unidades de Conservação.

A consideração dos aspectos sociais (figura 7) foram ignorados em grande parte dos processos, sendo identificado apreciação em apenas um dos processos, o caso da preferência por mão-de-obra local e a relação com a comunidade. $O$ item mais apreciado foi o quadro técnico com apenas $21 \%$ (3 de 14). Nota-se também o aparecimento de condicionantes

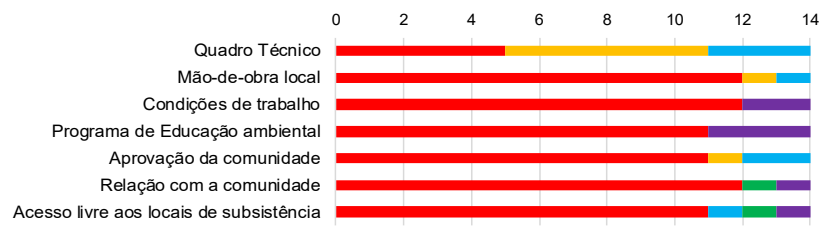

$$
\because N=D=A=A C \backsim C
$$

Figura 7-Análise dos Relatórios de Inspeçã̃o (RI) e/ou Parecer Técnico (PT) dos itens dos Aspectos Sociais dentre os 14 processos estudados. (N)Nãomencionado. (D)Apenas descrito. (A)Apreciado. (AC)Apreciado e proposto condicionante. (C)Apenas aparece como condicionante. sem nenhuma menção prévia no corpo do parecer relativos ao Programa de EducaçãoAmbiental, condições de trabalho, relação com a comunidade e o acesso aos locais de subsistência. Em apenas um dos processos analisados nesse trabalho foi possível notar a apreciação da maioria dos itens dos aspectos sociais.

\section{Condicionantes}

Dos processos analisados nesse trabalho, apenas 7 tiveram licença concedida e apresentaram condicionantes. Apenas um foi considerado processo atual (D2), os demais foram tidos como processos antigos, dos quais quatro foram licenças de operação (B1, D1, E1, F1) e dois de alteração (E2, F2).

O que se observa na análise dos condicionantes propostos é que muitos deveriam ser requisitos para a liberação da licença, ou seja, que deveriam ser considerados na apreciação técnica, uma vez que são informações importantes na decisão do parecer ou no mínimo vir a implicar em mudanças necessárias ao projeto. Alguns exemplos são: apresentar estudo técnico e/ou projeto relativo à viabilidade de implantação de lagoa de sedimentação para destinação das águas residuárias dos viveiros; apresentar autorização para averbação de reserva legal.Outro tipo de condicionante que deveria ser requerida pelos técnicos antes da liberação das licenças são a apresentação de programas e planos, para que pudessem ser avaliados previamente, como forma de garantir a adequação e qualidade dos mesmos, podendo aparecer como condicionante apenas sua execução. Os exemplos encontrados nos processos analisados são: Plano de Controle Ambiental do empreendimento; Plano de avaliação e acompanhamento da saúde do camarão; Diagnóstico do estado de conservação e Programa de Monitoramento das áreas de mangue de influência direta; Programa de monitoramento da qualidade das águas aduzidas aos viveiros e das águas sob impacto do efluente final; Programa de Gerenciamento de Resíduos Sólidos gerados no empreendimento; Programa de Recuperação de Áreas Degradadas; Programa de Monitoramento/Conservação da fauna terrestre na área de influência direta do empreendimento.

Ao analisar o cumprimento das condicionantes das licenças deferidas, pode-se notar, conforme observado na figura 8 , que apenas $33 \%$ das condicionantes foram devidamente atendidas e $8 \%$ não foram atendidas com justificativas aceitáveis. Grande parte das condicionantes que foram estipulados prazos para cumprimento das mesmas, seus prazos foram negligenciados e apenas apresentadas no momento da renovação das licenças, representando um total de $9 \%$ de condicionantes cumpridas fora do prazo e muitas ainda se encontravam pendentes (22\%). Por fim, 17\% simplesmente não foram atendidas 


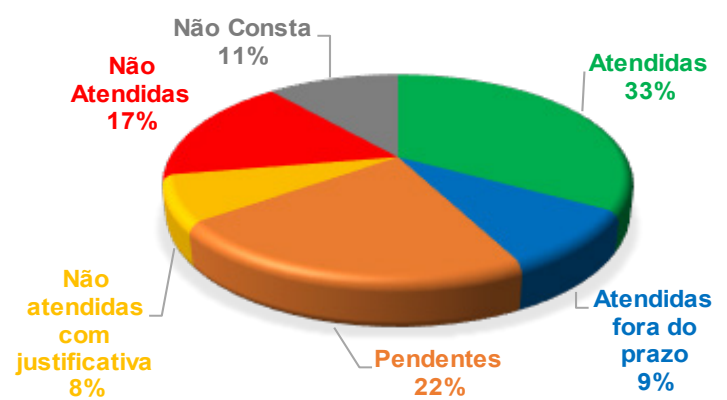

Figura 8 - Percentual da Avaliação de Condicionantes. Cálculo feito sobre o total de condicionantes dos 6 processos antigos analisados (total de 54 condicionantes).

e $11 \%$ não constam informações nos processos. Análise essa feita com base nas "Auto-avaliações" das condicionantes feitas pelo próprio requerente e exigidas pelo órgão no momento da renovação das licenças, podendo, então, ser feita apenas com os processos antigos deferidos (B1, D1, E1, E2, F1 e F2).

\section{DISCUSSÃO}

Para oLicenciamentoAmbiental cumprir seu papel preventivo, ele precisa ser capaz de avaliar o potencial de impacto da atividade, face as condições ambientais, no local que pretende se instalar. Essa avaliação deve resultar do confronto entre ações de intervenções e interações previstas e as restrições e/ou capacidade de suporte dos recursos ambientais potencialmente atingidos. Essa avaliação poderá propiciar também a indução de alternativas sustentáveis.

Nesse propósito, a apreciação necessária requer que essas informações sejam requeridas ainda na fase de planejamento do empreendimento, durante a requisição da Licença Prévia (LP), possibilitando que o projeto possa buscar a melhor escolha locacional de concepção e tecnológica antes da instalação da atividade. Após aprovação do projeto é que se requisita a Licença de Instalação e em seguida a de Operação.

Contudo, a situação da maioria dos processos de licenciamento ambiental de carcinicultura encontrados no Estado da Bahia, é de empreendimentos que já operam desde a década de 80/90, ou mesmo antes, e que para se regularizar, diferente da sequência preventiva, se direciona a licença de operação/regularização, de cunho meramente corretivo.

Esse aspecto compromete ou restringe bastante o propósito preventivo do LA, conforme destacado em trecho de um dos pareces técnicos analisados:

"[...] muitos empreendimentos de cultivo de camarão foram localizados, implantados e/ou se encontram em operação a revelia da legislação ambiental relacionada a atividade. Tal situação configura um imenso problema quando estes empreendedores requerem o licenciamento com a justificativa de que precisam se regularizar ambientalmente"(Processo C1, Parecer Técnico 0507/2006 - 0960, 2006, p. 1-2).
Diante desses pedidos de regularização, o órgão ambiental acaba tendo que requisitar as informações que seriam equivalentes a Licença Prévia durante a Licença de Regularização, mesmo sabendo que a situação restringe o objetivo de prevenção do LA, restando a tentativa de se buscar a minimização das ações impactantes e possível redução dos danos.

$\mathrm{Na}$ análise, o conteúdo das informações entregues pelos proponentes, em muitos casos se observa a precariedade das informações fornecidas e a dificuldade dos técnicos para conseguir utilizar essas informações nas suas análises. O que corrobora com essa constatação são as diversas notificações anexadas aos processos requerendo revisão das informações ou complementação das informações entregues ao órgão. Essa percepção está de acordo com alguns trabalhos, nos quais os autores Lima (2004) e Passos (2010), constataram que este seria um dos principais problemas que causam a morosidade processual ou a não liberação da licença.

Vale ressaltar que, dentre os processos analisados apenas 2 tiveram pareceres desfavoráveis à licença, o A1 e o C1, por serem localizados em áreas de manguezal consideradas de Preservação Permanente. Importante ressaltar, que os dois processos foram apreciados anteriormente ao novo Código Florestal (Brasil, 2012).

Ao se analisar os dados do quadro 2 pode-se constatar que não há correlações claras entre as análises dos itens explorados nos RI/PT e a faixa temporal dos processos. Apesar de atualmente serem requeridas mais informações nos processos, no geral, isso não implicou em um aumento ou melhoria dos itens analisados nos pareceres. Uma vez que a maioria dos itens não são mencionados $(N)$ ou são apenas descritos (D) sem nenhuma apreciação, pode-se interpretar que a maioria das informações são aceitas pelo técnico.

Em relação aos aspectos sociais foi possível notar somente uma apreciação da maioria desses itens. Esse processo buscou estabelecer contato com a comunidade através da Associação de Pescadores e Marisqueiras do local e entrevistou o presidente e marisqueiras associadas. Diante da sua relevância para a apreciação devida do LA, esse contato com a comunidade local deveria ser incorporado como prática sistemática dos órgãos ambientais como protocolo de inspeção.

No geral, conforme os resultados sugerem, o grupo de itens apreciados que apresentou um maior número de apreciações foi o de Interferências e dentro dele os itens mais apreciados foram: interferência em APP e manguezal; impactos na flora; e lançamento de efluentes. Esse destaque em relação aos itens supracitados está compatível com as principais 
preocupações em relação a atividade. Inclusive, em entrevista com agentes das empresas visitadas, foi afirmado que o maior entrave, atualmente, para a liberação das licenças são as exigências quanto a implantação de lagoas de decantação nas fazendas. Os demais itens, na maioria dos casos, foram negligenciados, principalmente os relativos aos impactos sociais, mostrando o descompromisso com a resolução dos conflitos sociais, não só pelas empresas, como também, pelo órgão ambiental. Postura essa, que deve ser mudada, se o intuito for diminuir os impactos gerados pela atividade e melhorar a visão da população sobre a atividade.

Assim, como esperado, ao compararmos os grupos, o que apresentou um maior número de apreciações foi o de Interferências, já que corresponde a uma análise dos efeitos da atividade. Em contrapartida, os itens como aspectos produtivos e insumos apresentaram poucas apreciações, o que demonstra um comportamento de análise do órgão ambiental baseado em ações corretivas, ao invés de buscar analisar e incentivar a não geração ou redução substancial de resíduos e a prevenção de impactos. Essa prática vem confirmar as constatações indicadas por Bezerra \& Munhoz (2000) e Pinha (2006), no qual diz que oarcabouço de regulação ambiental da atividade está focado nas abordagens de comando e controle e de "fim de tubo" (ações corretivas ou de tratamento de resíduos gerados no final do processo produtivo).

No geral, os pareceres mostraram-se pouco efetivos ao que diz respeito à aplicação dos princípios de precaução e prevenção e ao incentivo a adoção de práticas sustentáveis por parte dos empreendedores. Quase não foram mencionadas palavras como prevenção, redução, reciclagem e reutilização.

Os dados referentes à figura 8 , da avaliação das condicionantes, reforçam a necessidade de que itens importantes sejam requeridos antes da liberação das licenças para garantir seu cumprimento, já que no mínimo 48\% (soma das condicionantes não atendidas, pendentes e atendidas fora do prazo) das condicionantes não foram atendidas como deveriam. Isso sem contar com os $11 \%$ das condicionantes que simplesmente não constavam nas auto-avaliações, pois se acrescidas poderia chegar a um total de $59 \%$ de condicionantes indevidamente atendidas.

Outra constatação preocupante aparece ao se analisar o histórico de infrações e penalidades de cada empreendimento, apensados nos processos. Notou-se que a maioria teve períodos de operação sem licença e em alguns casos nunca a obtiveram e mesmo assim continuaram operando. E por algum motivo, todos, com exceção de um, possuem atos de advertência ou penalidades constados nos processos, aplicados pelo órgão ambiental, na tentativa de obrigar-los a se regularizarem. Todos acabam por solicitar a licença, porém, metade deles estavam com processo arquivado por falta de resposta do empreendedor a alguma solicitação de informação do órgão ambiental. E concomitantemente a isso, alguns conseguiram liminar judicial ou mandato de segurança para continuar atuando sem licença até a finalização dos processos. Fato que acaba por corroborar para a ineficácia dessas penalidades e do licenciamento ambiental frente aos empreendimentos de carcinicultura, pois incentiva o descaso frente às decisões do órgão ambiental.

\section{CONCLUSÃO}

O licenciamento ambiental é um dos poucos instrumentos de gestão ambiental que atualmente está implantado e ativo no Brasil. Por isso, seu objetivo de compatibilizar empreendimentos e atividades consideradas efetiva ou potencialmente poluidoras com os critérios capazes de garantir a sua sustentabilidade, o torna ainda mais importante e necessário para assegurar a qualidade ambiental de forma preventiva e subsidiar as tomadas de decisão do poder público no país. Entretanto, todos os processos disponíveis para estudo no órgão ambiental da Bahia tiveram como primeira licença, a de regularização e, diante desse fato, não foi possível analisar o caráter preventivo do LA.

A partir dos resultados das análises dos itens apreciados nos Pareceres do órgão ambiental notou-se um maior nível de apreciações no grupo de Interferências, que representa as consequências da atividade, ao invés de itens relativos aos aspectos produtivos e insumos. Assim, sugerem que o comportamento de apreciação do órgão ambiental está baseado em ações de "fim de tubo", em detrimento a não geração de resíduos e danos.

Os itens relativos aos aspectos sociais foram, claramente, ignorados em quase todos os pareceres técnicos analisados. Recomenda-se, portanto, a necessidade de se institucionalizar a participação da comunidade como parte do protocolo de inspeção, pois até então, os conflitos sociais são descritos pelo próprio requerente da licença e, normalmente, não se verifica a congruência com a opinião da comunidade local.

Ao analisar o cumprimento das condicionantes se constata que a maioria significativa não são devidamente atendidas. Este aspecto reforça a necessidade de que requisitos importantes sejam determinados para a liberação das licenças.

As limitações para o alcance de uma carcinicultura sustentável vêm desde os elementos normativos e gerenciais disponíveis, passando por retrocessos normativos, até a precarização do órgão estadual que não possui o suporte operacional suficiente para exercer de forma apropriada o Licenciamento Ambiental 
e a fiscalização da atividade.

O LA possui uma capacidade muito maior de auxiliar no desenvolvimento sustentável, porém os procedimentos e as práticas existentes estão muito aquém do mínimo necessário, se tornando um procedimento meramente cartorial. Por isso, é que apesar das iniciativas de enfraquecimento e eliminação do LA, esse instrumento deve ser fortalecido, pois o pouco que temos de prevenção, controle e gestão ambiental no nosso País, se deve ao Licenciamento Ambiental.

\section{REFERÊNCIAS}

Agra Filho, S.S. 2014. Planejamento e Gestão Ambiental no Brasil: os instrumentos da Política Nacional de Meio Ambiente. $1^{\text {a }}$ Edição. Elsevier, Rio de Janeiro, $248 \mathrm{p}$.

Assad, L.T. \& Bursztyn, M. 2000.Aquicultura sustentável. In: CNPq (ed.) Aquicultura no Brasil: bases para um desenvolvimento sustentável. Ministério da Ciência e Tecnologia. 33-72p.

Bahia. Decreto n 14.024 de 06 de junho de 2012. Aprova o Regulamento da Lei ${ }^{\circ} 10.431$, de 20 de dezembro de 2006, que instituiu a Política de Meio Ambiente e de Proteção à Biodiversidade do Estado da Bahia, e da Lei $n^{\circ} 11.612$, de 08 de outubro de 2009, que dispõe sobre a Política Estadual de Recursos Hídricos e o Sistema Estadual de Gerenciamento de Recursos Hídricos. Diário Oficial do Estado da Bahia, Salvador, 7 jun. 2012.

Bahia Pesca. Disponível em: <http://www.bahiapesca. ba.gov.br/modules/conteudo/conteudo. php?conteudo=14>. Acesso em: 28 jul. 2016.

Bezerra, M.C.L. \&Munhoz, T.M.T. 2000. Gestão dos Recursos Naturais: subsídios à elaboração da Agenda 21 brasileira. Ministério do Meio Ambiente; Instituto Brasileiro do Meio Ambiente e dos Recursos Naturais Renováveis; Consórcio TC/BR/ FUNATURA, Brasília, 200p.

Brasil. Lei n 12.651, de 25 de maio de 2012. Dispõe sobre a proteção da vegetação nativa. Diário Oficial, Brasília, 25 mai. 2012.

Resolução CONAMA n 312, de 10 de outubro de 2002. Dispõe sobre o licenciamento ambiental dos empreendimentos de carcinicultura na zona costeira. Diário Oficial, Brasília, 18 out. 2002.

Resolução CONAMA n 459, de 16 de outubro de 2013. Altera a Resolução n 413, de 26 de junho de 2009, do Conselho Nacional do Meio AmbienteCONAMA, que dispõe sobre o licenciamento ambiental da aquicultura, e dá outras providências. Diário Oficial, Brasília, 07 out. 2013.

FAO (Food and Agriculture Organization of the United Nations). 2006. Internacional principles for responsible Shrimp Farming. Network of
Aquaculture Centres in Asia-Pacific (NACA), Bangkok, 20p.

Lima, A.C.F. 2004. Carcinicultura marinha no litoral da Bahia: licenciamento ambiental como instrumento para a sustentabilidade. Tese de Mestrado. Centro de Desenvolvimento Sustentável, Universidade de Brasília. 160p.

Meireles, A.J.A.; Cassola, R.S.; Tupinambá, S.V. \& Queiroz, L.S. 2007. Impactos ambientais decorrentes das atividades da carcinicultura ao longo do litoral cearense, nordeste do Brasil. Mercator. 12 (1): 83-106.

Montibeller, G. 2003. Maricultura e meio ambiente: a experiência da Escócia como alerta para o Brasil. Textos de economia. 8(1): 193-206.

MPA (Ministério da Pesca e Aquicultura) 2015. Plano de desenvolvimento da Aquicultura Brasileira 2015/2020. Brasília, 59 p.

Oliveira, C.M.F.V. 2012. Licenciamento Ambiental. Monografia de Pós-Graduação. Faculdade de Direito, Universidade Federal do Rio Grande do Sul. $123 \mathrm{p}$.

Passos, A.L.O. 2010. Carcinicultura Marinha: caracterização e conflitos entre as esferas ambiental e produtiva no município de Jaguaripe, Bahia. Monografia - Instituto de Geociências, Universidade Federal da Bahia. 77 p.

Pinha, C.C.C.L. 2006. Incorporação da produção mais limpa em carcinicultura: subsídios para uma gestão eco-compatível. Dissertação de Mestrado - Gerenciamento e Tecnologias Ambientais no Processo Produtivo, Universidade Federal da Bahia, Salvador. $185 \mathrm{p}$.

Rocha, I.P. 2015. Cultivo do Camarão Marinho: Atividade Socialmente Justa, Ambientalmente Responsável e, Economicamente Importante, de Forma Especial para o Meio Rural da Região Nordeste. ABCCAM. 8p. Disponível em: <http:// abccam.com.br/site/wp-content/uploads/2015/05/ Carcinicultura-Marinha-Brasileira-ArtigoExecutivo.pdf>. Acesso em: 11 set.2018.

Santos, M.F. \& Mattos, S.M.G. 2009. Avaliação do potencial aquícola em corpos d'água de domínio da União no Estado de Pernambuco. Revista Brasileira de Engenhara de Pesca. (1): 110-123.

Scherer, M.; Sanches, M. \& De Negreiros, D.H. 2010. Gestão das zonas costeiras e as políticas públicas no Brasil: um diagnóstico. In: Barragán Muñoz, J.M. (coord.) Manejo Costero Integrado y Política Pública enlberoamérica: Un diagnóstico. Necesidad de Cambio. Red IBERMAR (CYTED). 291-308p.

Submetido: Setembro/18 Revisado: Dezembro/19 Aceito:Dezembro/19 Publicado: 09/11/2020 